\title{
Work Engagement and Machiavellianism in the Ethical Leadership Process
}

\author{
Deanne N. Den Hartog • Frank D. Belschak
}

Published online: 5 April 2012

(C) The Author(s) 2012. This article is published with open access at Springerlink.com

\begin{abstract}
Leaders who express an ethical identity are proposed to affect followers' attitudes and work behaviors. In two multi-source studies, we first test a model suggesting that work engagement acts as a mediator in the relationships between ethical leadership and employee initiative (a form of organizational citizenship behavior) as well as counterproductive work behavior. Next, we focus on whether ethical leadership always forms an authentic expression of an ethical identity, thus in the second study, we add leader Machiavellianism to the model. For Machiavellian leaders, the publicly expressed identity of ethical leadership is inconsistent with the privately held unethical Machiavellian norms. Literature on surface acting suggests people can at least to some extent pick up on such inauthentic displays, making the effects less strong. We thus argue that the positive effects of ethical leader behavior are likely to be suppressed when leaders are highly Machiavellian. Support for this moderated mediation model was found: The effects of ethical leader behavior on engagement are less strong when ethical leaders are high as opposed to low on Machiavellianism.
\end{abstract}

Keywords Machiavellianism - Ethical leadership · Work engagement - Counterproductive work behavior - Personal initiative $\cdot$ Ethical identity

D. N. Den Hartog $(\varangle)$ · F. D. Belschak

Amsterdam Business School, University of Amsterdam,

Plantage Muidergracht 12, 1018 TV Amsterdam,

The Netherlands

e-mail: d.n.denhartog@uva.nl

F. D. Belschak

e-mail: f.d.belschak@uva.nl
The pressure on firms and their leaders to behave ethically has increased due to the media attention and government regulation efforts following recent business scandals. Ethical behavior is now critical to leaders' credibility and their potential to meaningfully influence followers at all levels in the organization (e.g., Piccolo et al. 2010). Ethical leadership can be defined as "the demonstration of normatively appropriate conduct through personal actions and interpersonal relationships, and the promotion of such conduct to followers through two-way communication, reinforcement, and decision-making" (Brown et al. 2005, p. 120). The research on ethical leadership to date shows that ethical leaders inspire high levels of commitment and trust and foster desirable behaviors among followers (e.g., Brown et al. 2005; Den Hartog and De Hoogh 2009; Kalshoven et al. 2011a; Piccolo et al. 2010).

Ethical leadership like charismatic leadership is a valuedriven form of leadership. Such value-driven leaders affect the self-concept and beliefs of their followers and, in turn, their motivation, attitudes, and behaviors (e.g., Shamir et al. 1993). For example, Piccolo et al. (2010) suggest that ethical leader behavior helps followers see their job as more meaningful, which translates into showing increased motivation, effort, and productive behavior. An important way in which ethical leaders affect the self-concept and beliefs of followers is through acting as role models for their followers (Brown et al. 2005). According to this social learning perspective, followers imitate favorable behaviors of their ethical leaders' expressed identity and adopt the leader's emphasis on integrity, trust, and shared values by integrating these into their own identity (e.g., Brown et al. 2005).

Here, we build on this identification-based motivation process and propose that the emphasis on shared moral values and the honesty, caring, and fairness modeled by ethical leaders will foster employees' work engagement, 
which in turn enhances pro-organizational and decreases counterproductive work behavior. Work engagement is defined as a positive, fulfilling work-related motivational state of mind characterized by vigor, dedication, and absorption (Schaufeli et al. 2006). In our first study, we thus test a mediation model that suggests engagement mediates between ethical leadership and employee behavior.

In addition, related work on transformational leadership distinguishes between authentic transformational leaders, who are ethical, genuine, and use power to attain moral and social end-values, and pseudo-transformational (inauthentic) leaders, who are self-interested, seek power at the expense of others and lack morality (e.g., Bass and Steidlmeier 1999). Is this also the case for ethical leadership? Can followers rate the behavior of leaders as ethical even when these leaders really are not moral people? With the increased pressure on managers to act ethically, are some leaders trying to foster an ethical image for impression management or reputation building reasons even when this is not in line with their private beliefs; and if so, do such leaders have the same positive impact on their followers as authentic ethical leaders? Qualities like integrity or honesty that are ascribed to ethical leaders imply that they are characterized by authentically moral values and ethical identities (that is, that they are not only moral managers but also are moral people, cf. Brown and Treviño 2006). From an identity perspective, however, one might also argue that ethical leader behavior may also form an expressed or public identity that is not necessarily commensurate with privately held values and beliefs (cf. Hawley 2003).

In our second study, we try to address this issue by taking leader Machiavellianism into account. Machiavellianism is defined as a strategy of social conduct that involves manipulating others for personal gain (Wilson et al. 1996, p. 295). We argue that these manipulative Machiavellians may (inauthentically) display ethical leader behaviors if they perceive this is a useful way to reach their goals even though they privately hold less moral beliefs. However, we argue that the positive impact of ethical leadership on engagement will be reduced for those leaders for who private identity and expressed identity are not in line as followers are likely to pick up on inauthentic displays (see e.g., Zapf 2002). Thus, we build on the mediation model from Study 1 by introducing leader Machiavellianism as a moderator and testing a moderated mediation model in Study 2.

\section{Ethical Leadership}

The expression of a moral identity in leader behavior or in other words the ethical behavior of leaders is receiving increasing attention in leadership research and such leaders have a strong impact on followers (e.g., Brown and Treviño 2006). Identification-based motivational and social learning processes form an important underlying mechanism that explains the impact of ethical leadership on followers. Ethical leadership is a value-driven form of leadership that affects the self-concept and beliefs of followers. This, in turn, affects their motivation, attitudes, and behaviors (e.g., Shamir et al. 1993). One way in which ethical leaders are argued to affect the self-concept and beliefs of followers is through acting as role models for their followers (Brown et al. 2005). They show ideological (ethical) behavior and thus serve as role models for ethical and moral values.

Value-driven leaders engage in communicative processes to amplify certain values and identities, and they suggest linkages between behaviors they expect from their followers, the amplified values and identities, and their vision of a better future (Shamir et al. 1993). Similarly, the literature on ethical leadership (e.g., Brown et al. 2005; Kalshoven et al. 2011a) argues that the communication and outward rewarding of ethical values and behaviors is an important element of ethical leadership. In addition, by acting as a role-model and aligning followers' frames through communicative processes leaders articulate and transfer ideals to followers thus providing a sense of identity: the leader's values and ideas become part of followers' self-concept through value internalization and identification with such desirable values (Shamir et al. 1993). These changes in followers' self-concept toward more collective values and a collective identity (stressing the common good rather than selfish needs) increases attachment to the collective and their willingness to make personal sacrifices.

Ethical leaders send clear messages about ethical values and hold subordinates accountable for their actions (Treviño et al. 2003). Ethical leaders show what Brown et al. (2005, p. 120) label "normatively appropriate conduct through personal actions and interpersonal relationships". In other words, they model appropriate expression of an ethical identity for followers. Their actions make ethical and moral goals explicit and show followers how they can contribute to attaining such goals. Followers are likely to respect such value-driven leaders and to identify with and emulate the values and behavior of these leaders (e.g., Brown and Treviño 2006). Ethical leader behaviors include acting fairly, promoting and rewarding ethical conduct, allowing follower voice, showing concern, demonstrating consistency and integrity, and taking responsibility for one's actions (Brown et al. 2005; De Hoogh and Den Hartog 2008; Kalshoven et al. 2011a; Treviño et al. 2003). Research shows that ethical leadership is related to, but also empirically distinguishable from transformational and other leadership styles and that ethical leadership explains additional variance in outcomes beyond these styles (see e.g., Brown et al. 2005; Kalshoven et al. 2011a, b). 


\section{Ethical Leadership, Initiative, and Counterproductive Work Behavior}

Ethical leadership implicates the self-concept and beliefs of followers and helps to make the work of followers more meaningful and motivating (e.g., Piccolo et al. 2010). Ethical leadership has thus been argued and found to be related to followers' organizational citizenship behaviors (OCB) (Brown and Treviño 2006; Mayer et al. 2009; Piccolo et al. 2010; Kalshoven et al. 2011a; Walumbwa and Schaubroeck 2009). Here we include a specific form of citizenship, namely employee initiative which refers to proactive citizenship behavior (e.g., Frese et al. 1996, 1997; Frese and Fay 2001) and captures employees' change-oriented and voice behaviors (e.g., Rank et al. 2004). Initiative is part of what the literature labels challenging OCB, which includes behaviors such as voicing opinions and ideas or taking the initiative to provide suggestions for change (e.g., Van Dyne and LePine 1998).

Frese and Fay (2001) define personal initiative as "work behavior characterized by its self-starting nature, its proactive approach and by being persistent in overcoming difficulties that arise in the pursuit of a goal" (p. 134). Personal initiative describes employees' taking the responsibility to anticipate and their actively changing the environment or the self to have meaningful impact and improve the organization. Initiative often involves a constructive challenge to the status quo (cf. Moon et al. 2008). Initiative includes recommending changes even when others disagree, taking initiative to improve circumstances at work, and solving problems even before being asked to do so (Bolino and Turnley 2005; Den Hartog and Belschak 2007; Frese, and Fay 2001; Van Dyne and LePine 1998).

We expect that ethical leaders are especially important for employees to be willing to engage in OCB in general and show initiative in particular, for several reasons. Ethical leaders treat employees fairly and are trusted by their employees who, in turn, are likely to experience the relationship with their leader as a positive social exchange relationship which they reciprocate by helping the organization in a variety of ways (Mayer et al. 2009). An ethical leader will try to keep promises (Kalshoven et al. 2011a), which suggests that employees trust that any obligations they see on the side of the leader will be fulfilled. As a reaction, they are themselves likely to feel a personal obligation to contribute positively to the exchange, and taking initiative on behalf of the organization can form such an exchange currency. Consistently, OCB has been shown to be linked to elements of ethical leadership such as employee trust in the leader (e.g., Dirks and Ferrin 2002; Konovsky and Pugh 1994), fair treatment from the leader (e.g., Pillai et al. 1999), and leader consideration (see Podsakoff et al. 2000).

In addition, ethical leadership is value driven and followers can strongly identify with the values the leader articulates and enacts (Brown and Treviño 2006). When employees care about and feel attached to their organization or leader, they will be more likely to embrace their values and goals and invest effort to attain these (Den Hartog and Belschak 2007). Taking initiative can be a means to achieve such work goals and values (e.g., Crant 2000). Also, ethical leaders are role models of responsible behavior (De Hoogh and Den Hartog 2008) and engaging in personal initiative would form an appropriate emulation of the behavior of ethical leaders. For instance, when realizing how work processes could be improved, followers of ethical leaders who model responsibility are likely to emulate this by acting responsibly themselves through taking the initiative to suggest or implement such improvements. Thus:

Hypothesis 1 Ethical leadership will be positively related to follower personal initiative.

Counterproductive work behavior (also labeled deviance or misbehavior) refers to negative employee behavior that is harmful to the organization or other employees (e.g., Chen and Spector 1992; Lee and Allen 2002; Marcus and Schuler 2004). These counterproductive acts at work can take different forms, for example theft, fraud, sabotage, absenteeism, or physical and verbal aggression. Marcus and Schuler (2004) hold that at the most general level, acts of counterproductive behavior have in common that they are volitional acts that violate the legitimate interests of an organization by being potentially harmful to its members or to the organization as a whole. Research shows that the way employees are treated by the organization and especially by their leader affects such behavior. For example, abusive supervision was found to relate positively to counterproductive behavior (Detert et al. 2007). In contrast, a meta-analysis by Cohen-Charash and Spector (2001) shows that both distributive and procedural justice relate negatively to such behavior.

In their review, Brown and Treviño (2006) propose that ethical leadership should be negatively linked to counterproductive behavior as such leaders are role models and followers will emulate their ethical behavior. In addition, ethical leaders use reward and punishment to enhance ethical conduct. They clarify standards of appropriate conduct and sanction rule violation. Also, the positive social exchange relationship employees are likely to develop with ethical leaders who treat them fairly, allow them voice, and act in a caring and respectful manner implies followers will want to reciprocate by showing 
positive behaviors. This makes it less likely that they show high levels of counterproductive behavior. Thus:

Hypothesis 2 Ethical leadership will be negatively related to follower counterproductive work behavior.

\section{The Role of Follower Work Engagement}

The social learning perspective suggests that followers imitate favorable behaviors of ethical leaders and adopt the leader's emphasis on integrity, trust, and shared values by integrating it into their identity (e.g., Brown et al. 2005). Indeed, Kalshoven and Den Hartog (2009) found that followers see ethical leaders as an ideal representation of the group's identity (that is, as more group prototypical and as prescribing appropriate attitudes and behaviors, cf. Hogg 2001). The process of identification implies that showing effort toward accomplishing the value-laden goals ethical leaders communicate becomes an intrinsically motivating expression of followers' self-concept (e.g., Shamir et al. 1993). Consistently, Piccolo et al. (2010) found that ethical leadership helps followers see their jobs as more meaningful, which translates into increased effort and productive behavior. Thus, followers of ethical leaders are likely to be more intrinsically motivated. Here, we combine these ideas and propose that ethical leaders stimulate employees' work engagement as engagement forms a unique motivational state that in turn enhances citizenship and decreases counterproductive work behavior (e.g., Bakker et al. 2004).

Work engagement is a positive motivational workrelated state characterized by vigor, dedication, and absorption (e.g., Schaufeli et al. 2002, 2006; Schaufeli and Bakker 2004). The element of vigor refers to experiencing high levels of energy and mental resilience while working, the willingness to invest effort in work, and persistence even in the face of difficulties. The element of dedication refers to a having sense of significance and meaning, inspiration, pride, enthusiasm, and challenge. Absorption is characterized by being concentrated and engrossed in work (e.g., Bakker et al. 2007).

Mauno et al. (2007) note that vigor has conceptual similarity with the concept of work motivation, whereas dedication relates more to the concept of job involvement. These elements of engagement seem especially relevant to the ethical leadership process. Value-based leadership that makes work more significant and meaningful to followers is likely to enhance their dedication to this work and their willingness to invest and persist even when things are difficult (cf. Piccolo et al. 2010). Also, trust (as induced by leader behavior) has been shown to increase employees' commitment (Pillai et al. 1999), a concept that is related to work engagement (Hallberg and Schaufeli 2006). In addition, allowing voice and asking for input should enhance a sense of ownership as well as pride at work. Thus, we suggest that (at least part of) the impact of ethical leaders on followers comes about through enhancing this positive motivational state of engagement (and especially vigor and dedication). Through stressing values that enhance followers' abilities to see the meaningfulness of their work, sharing power, showing fairness, care, and concern ethical leaders are likely to enhance followers' work engagement and, in turn, affect employee work behaviors such as enhancing initiative and lowering counterproductive behavior.

Although to our knowledge direct tests of this proposed relationship do not exist, related findings support this line of argumentation. In a study among teachers, Bakker et al. (2007) demonstrated that job resources including supervisor support significantly enhanced work engagement, especially when job strain (in this specific case pupil misbehavior) was high. Laschinger and Finegan (2005) showed that adequate rewarding and recognition by supervisors was significantly related to employee work engagement, and Halbesleben (2010) finds in a meta-analytic study that social support, feedback, positive organizational climate, and self-efficacy are positively associated with engagement. Clearly, although the relationship between ethical leadership and work engagement remains to be tested, these findings support our conceptual reasoning that a relationship is likely.

In turn, engaged individuals are likely to show more positive and less deviant work behaviors. First, work engagement comes with high levels of energy and activation as vigor is an important component of engagement. This energy encourages activity and proactive (as opposed to passive or reactive) behavior. Second, engagement is a positive emotional state and therefore likely to broaden a person's thought-action repertoire (e.g., Fredrickson 2001) by encouraging individuals to direct their attention at new behaviors and by stimulating initiation of new behavior. Den Hartog and Belschak (2007) show that positive affect (which is related to work engagement, see Rothbard 2001) was positively related to employee initiative. Here, we argue similarly that work engagement is related to initiative. Also, Bakker et al. (2004) found that engaged employees showed more citizenship behavior in general. Finally, as engaged employees are highly dedicated to their work it seems reasonable to assume that they will avoid (or at least reduce) activities that are likely to threaten or damage their work such as destructive/counterproductive work behaviors. Thus, we hypothesize:

Hypothesis 3 The relationship between ethical leadership and employees' initiative will be mediated by employees' work engagement. 
Hypothesis 4 The relationship between ethical leadership and employees' counterproductive work behavior will be mediated by employees' work engagement.

\section{Authentic and Inauthentic Ethical Leadership}

In the second study, we address whether demonstrated ethical leadership is always genuine and value-based, and we propose that highly manipulative Machiavellians may try to enact an ethical image if they feel this benefits them. Measures of ethical leadership rely on perceptions of the behavior of the leader by followers, thus they reflect a measure of perceived ethicality, yet whether such behaviors are always an authentic expression of morality of leaders is not clear. Here, we argue that outward ethical behavior can be seen as inauthentic if leaders privately hold inner norms and values that differ from their publicly demonstrated values and behaviors. Specifically, we refer here to the difference between privately held Machiavellian norms and values and publicly shown ethical conduct and behavior as a Machiavellian personality represents a deceitful and unethical value system which opposes moral values of ethical leaders. Machiavellianism is a strategy of social conduct that involves manipulating others for personal gain (Wilson et al. 1996). Machiavellians are seen as manipulators and cheaters who reduce the social capital of a group or organization (e.g., Gunnthorsdottir et al. 2002; Paulhus and Williams 2002). For example, Machiavellianism is positively related to salespersons' willingness to lie (Ross and Robertson 2000). Obviously, manipulating, cheating and lying do not come to mind as ethical behaviors of leaders. Brown and Treviño (2006) state: "In contrast to ethical leaders, Machiavellian leaders are motivated to manipulate others in order to accomplish their own goals. They have little trust in people and, in turn, tend not to be trusted by others" (p. 604). They hold that coercion and manipulation are not ethical sources of influence, and leaders who employ these tactics are unlikely to be seen as attractive ethical models by their followers. Coercion and manipulation are inconsistent with social learning which rests on the assumption that observers can freely select models to observe and emulate. Therefore, Brown and Treviño (2006) propose Machiavellianism and ethical leadership are negatively related.

However, this negative relationship between Machiavellianism and ethical leadership assumes that Machiavellians are always obvious in the expression of this trait, and that it is always clearly visible to subordinates that they are being lied to or manipulated. This is not necessarily the case though. Several researchers note that Machiavellians are able to show both pro-social and coercive strategies to successfully attain their goals (e.g., Hawley 2003). Machiavellians are adept at forming alliances and collaborate with others to promote their own interests. Machiavellian leaders are good liars and skilled at creating a desirable image (DePaulo and Rosenthal 1979). For example, Deluga (2001) found that Machiavellianism was positively related to charisma and perceived greatness of past US presidents. Machiavellians do not always engage in deception and manipulation. Rather, they are adaptable and may also invest in pro-organizational activities. They may act in a friendly and cooperative manner if they see this as beneficial to themselves (Wilson et al. 1996, p. 295). Machiavellians engage in impression management (Becker and O'Hair 2007) and they have been shown to be highly self-interested, goal driven, and emotionally detached from their (inter-)actions which leaves them able to fully focus on goal achievement (e.g., Cooper and Peterson 1980).

In many firms, the pressure of leaders to behave ethically has increased as public scrutiny is up due to the financial crisis and repeated ethical failures that were also in part caused by selfish, unethical management behavior, and businesses cannot afford more scandals. As more firms are creating explicit integrity or ethics norms and implementing codes of conduct, at least outwardly acting in an ethical way may be needed to be able to be successful as a manager, and showing ethical leader behavior may be required more explicitly than before. This suggests that showing ethical leadership can perhaps increasingly also be viewed as an expressed or public identity that is not necessarily commensurate with privately held norms and beliefs. In other words, displays of ethical leader behavior may not always be an authentic expression of identity and traits. The literature on emotional work/emotional labor (e.g., Zapf 2002) notes that individuals often 'act' in their workplace in the sense that privately felt and publicly expressed emotions differ from each other. Similarly, we propose Machiavellians may demonstrate or 'act' ethical leader behaviors when they feel this benefits them. Given that Machiavellians are characterized by a strong impression management motive (Bolino and Turnley 2003; Becker and O'Hair 2007), they are likely to show such ethical leader behavior if they see that as the best route to create a good reputation and attain their goals. In this sense, it is possible that Machiavellians invest in outwardly enacting ethical leader behaviors to manage the impression of others and come across better.

In the work on transformational and charismatic leadership, a similar question has been raised on the role of leader morals. For example, a distinction has been made between authentic and pseudo-transformational leaders (Bass and Steidlmeier 1999; Barling et al. 2008; Parry and Proctor-Thomson 2002). Authentic transformational leaders are characterized by behavior that is "true for themselves and for others", that is, these leaders are willing to 
sacrifice their personal goals for collective goals and truly aim for the greater good. Pseudo-transformational leaders do not "practice what they preach", i.e., they do not transform their individual goals into collective goals and are not willing to sacrifice their self-interests. This distinction also mirrors earlier work by Howell and Avolio (1992) who similarly distinguish between personalized charismatic leaders motivated by self-interests and personal power versus socialized charismatic leaders who are concerned for the common good. As Bass and Steidlmeier (1999, p. 186) note: "It is the presence or absence of such a moral foundation of the leader as a moral agent that grounds the distinction between authentic versus pseudotransformational leadership." Thus, while the outwardly focused behaviors of leaders may be the same, the moral foundation may differ across different leaders.

Drawing on this tradition, we posit in an analogous way that leaders who show similar ethical leader behavior may be authentic or inauthentic, that is, they may be nonmanipulative and have personally strong ethical norms (Non-Machiavellians) or they may be strongly manipulative and have rather unethical norms (Machiavellians). As Dasborough and Ashkanasy (2002) note it is hard for followers to see the difference between authentic and nonauthentic leaders as while the intentions of such leaders differ, the behaviors they display are highly similar. Here, we test whether followers indeed are able to pick up on authentic or less-authentic displays of ethical leadership. We investigate how followers react in case of conflicts between the leader's expressed, public identity (perceived ethical leader behavior) and their private identity (leader Machiavellian personality). Followers may recognize signals of leaders' underlying motives and moral foundation if they are not in line with their behavior. Consistently, Barling et al. (2008) found that followers show significantly different (more negative) emotional and attitudinal reactions to pseudo-transformational leadership than to authentic transformational leadership.

The literature on emotional work similarly notes that authentic expression of emotions is perceived differently and more positively by others than "faking" emotions (surface acting: expressing emotions that differ from one's real inner feelings) (Hochschild 1983; Ashforth and Humphrey 1993; Zapf 2002). We therefore suggest that the positive impact of ethical leader behavior on engagement is reduced for those leaders for who private identity and expressed identity are not in line (in other words, when Machiavellians are acting as ethical leaders). The inauthenticity of showing ethical behavior and publicly stressing values that are not privately held may shine through thereby making the expression of ethical leader behavior less powerful in its impact on others (Zapf 2002). We therefore hypothesize that the relationship between ethical leadership and follower work engagement is moderated by leaders' scores on Machiavellianism. Specifically, if ethical behavior is inauthentic (that is displayed by manipulative and deceitful Machiavellians) the positive relationship between shown ethical leader behavior and follower engagement is likely to be weaker than if ethical behavior is authentic (shown by non-manipulative Non-Machiavellians). Thus, we further build on the mediation model above by introducing leader Machiavellianism as moderator in a moderated mediation model. Thus, we hypothesize:

Hypothesis 5 The mediated relationship of ethical leadership with both initiative and counterproductive behavior will be moderated by leader Machiavellianism. Specifically, the relationship between ethical leadership and follower work engagement will be weaker for high Machiavellian than for low Machiavellian leaders.

\section{Method}

\section{Procedure and Sample}

In both studies, we have matched samples of subordinates and leaders (Study 1: $n=167$; Study 2: $n=200$ ). For both studies, employees and supervisors were provided questionnaires with stamped return envelopes and a letter explaining the study and the confidential and voluntary nature of participation. Responses were sent directly to the researchers, who were available to answer questions. Only questionnaires for which a matching supervisor-employee evaluation was obtained and that were completely filled out were included in the analyses. In both studies, employees rated their leaders on ethical leader behaviors and reported their own counterproductive behavior and work engagement; leaders reported on employees' productive work behavior (personal initiative) and in Study 2 leaders also reported on their own personality (Machiavellianism). All survey measures we used were validated measures from the literature that if needed were carefully translated and backtranslated to ensure correct meaning; all items were administered in Dutch.

The final sample consisted of 167 complete supervisoremployee dyads in Study 1 and 200 employee-supervisor dyads in Study 2. All respondents participated voluntarily and anonymously and did not receive anything in return for participation. Respondents (focal employees) worked in a wide range of jobs including lawyers, salespersons, account managers, customer service employees, and consultants. Of the respondents in Study 1, $61 \%$ were men; the average age of respondents was 34 years $(S D=9.96)$. On average, they had worked for their current employer for 5.8 years $(\mathrm{SD}=6.7)$, and $42 \%$ had successfully finished an academic 
Table 1 Descriptives and correlations between the variables (Cronbach's alpha's on diagonal)

Study 1: $N=167$. Study 2:

$N=200 . * p<.05 . * * p<.01$

education (either at undergraduate or graduate level). Of the respondents in Study 2, $53 \%$ were men. Here, respondents were 31 years old on average $(\mathrm{SD}=11.42)$ and had an average tenure of 5.2 years $(\mathrm{SD}=7.54)$. $31 \%$ held an academic degree (either at undergraduate or graduate level).

\section{Measures}

In Study 1, employees' personal initiative was measured as a supervisor rating; all other variables were measured as self-ratings. To measure employees' perception of their leader's ethical leadership behavior we took the well-validated 10-item scale by Brown et al. (2005) (e.g., "My leader discusses business ethics or values with employees", "...sets an example of how to do things the right way in terms of ethics"). Cronbach's alpha was .91 .

Work engagement was measured by the Dutch form of the 9-item short Utrecht Work Engagement Scale developed by Schaufeli and Bakker (2004). It consists of items on vigor, absorption, and dedication (e.g., "When I get up in the morning, I feel like going to work", "I am immersed in my work", and "I am enthusiastic about my job"). Cronbach's alpha was .92 .

Personal initiative was measured with 7 items (e.g., 'I take initiative immediately, even when others don't') developed by Frese et al. (1997). Cronbach's alpha was 91. Counterproductive work behaviors were measured with 11 items developed by Fox and Spector (1999) covering both minor and more serious counterproductive behaviors directed at the organization (e.g., "I purposively do not work hard when there are things to be done"). Cronbach's alpha was .93 .

In Study 2, we used the same measures as in Study 1. Reliabilities for all measures were high, ranging from .88 (ethical leadership) to .93 (supervisor-rated personal initiative) (see Table 1). In addition, supervisors rated their degree of Machiavellianism with the 8-item version of the
Mach-IV scale of Christie and Geis (1970), currently still the most used measure of Machiavellianism (e.g., Deluga 2001; Paulhus and Williams 2002). Cronbach's alpha was .84 .

In both studies, responses for all items were given on a 7-point scale ( $1=$ 'completely disagree' to $7=$ 'completely agree').

\section{Results}

Measurement Model

To test the factor structure as well as the convergent and discriminatory validity of our scales, we conducted a factor analysis of the measures in both studies. The goodness-of-fit of the models was assessed with Chi-square tests, the root mean square error of approximation (RMSEA), the comparative fit index (CFI), and the incremental fit index (IFI). Discussions of these indices are found in Bentler (1990), Browne and Cudeck (1993), and Marsh et al. (1996). In Study 1 , the confirmatory factor analysis showed a satisfactory fit of the hypothesized four factor structure (i.e., ethical leadership, engagement, initiative, and counterproductive behavior): $\chi^{2}(605)=1050.90(p<.01)$; CFI $=$ $.90 ;$ IFI $=.90 ;$ RMSEA $=.07$. Factor loadings ranged from .59-.88 for ethical leadership, from .61-.90 for engagement, from .70-.82 for initiative, and from .57-.92 for counterproductive behavior. The factor inter-correlations ranged from -.50 (engagement and counterproductive behavior) to .63 (ethical leadership and engagement). In Study 2, the data supported the hypothesized five factor structure (i.e., leader Machiavellianism, ethical leadership, engagement, initiative, and counterproductive behavior). The confirmatory factor analysis yielded satisfactory results: $\chi^{2}(906)=1439.48(p<.01)$; CFI $=.90$; IFI $=$ $.90 ;$ RMSEA $=.06$. Factor loadings ranged from .55-.71 
for Machiavellianism, from .55-.79 for ethical leadership, from .55-.84 for engagement, from .68-.92 for initiative, and from .43-.75 for counterproductive behavior. The factor inter-correlations ranged from -.34 (initiative and counterproductive behavior) to .55 (ethical leadership and engagement).

\section{Mediation Analyses}

Descriptives, inter-correlations, and reliabilities of the scales for both studies are presented in Table 1. In both studies the correlations between ethical leadership, work engagement, personal initiative, and counterproductive work behavior are in the expected direction. That is, ethical leadership relates positively to work engagement and initiative and negatively to counterproductive work behavior; engagement relates positively to initiative and negatively to counterproductive behavior. In addition, although leader Machiavellianism is slightly negatively correlated with ethical leadership, this relationship is not significant.

In Study 1, to test the hypothesized relationship between ethical leadership and outcomes as well as the meditation of work engagement, we conducted hierarchical regression analyses. In the analyses we entered ethical leadership in Step 1 and added work engagement in Step 2. The results show that ethical leadership and work engagement explain more variance in counterproductive work behavior (24\%) than in personal initiative $(15 \%)$.

Ethical leadership has a significant main effect on both employees' initiative $(\beta=.29, p<.01, F=14.16$, $\left.R^{2}=.08\right)$ and their counterproductive behavior $(\beta=$ $\left.-.26, p<.01, F=11.90, R^{2}=.07\right)$. Hypotheses 1 and 2 are thus supported by the data. Similarly, work engagement is significantly related to initiative $(\beta=.39, p<.01$, $\left.F=27.91, R^{2}=.15\right)$ and counterproductive behavior $\left(\beta=-.50, p<.01, F=52.78, R^{2}=.24\right)$. A separate regression analysis showed that, ethical leadership is significantly positively related to engagement $(\beta=.54$, $p<.01, F=69.06, R^{2}=.30$ ).

After entering ethical leadership into the regression equation in Step 1, work engagement is entered in Step 2 for both employee initiative and counterproductive work behavior. When looking at Step 2 for initiative, the increase in explained variance by adding engagement is significant $\left(\Delta R^{2}=.07, F\right.$ change $\left.=14.16, p<.01\right)$; for counterproductive behavior, the increase in explained variance is also significant $\left(\Delta R^{2}=.17, F\right.$ change $\left.=37.92, p<.01\right)$. In both cases, work engagement is significantly related to the dependent variable when controlling for ethical leadership (initiative: $\beta=.33, p<.01$; counterproductive behavior: $\beta=-.50, p<.01$ ). Also, the main effects (beta weight) of ethical leadership decrease substantially when work engagement is added to the equation and drop to a non- significant level (initiative: $\beta=.10$, n.s.; counterproductive behavior: $\beta=.01$, n.s.). A Sobel test (see Sobel 1982) shows that the decrease is significant for both personal initiative (effect size $=4.46, p<.01$ ) and counterproductive work behavior (effect size $=-5.46, p<.01$ ). Thus, the effects of ethical leadership on both dependent variables are fully mediated by work engagement, supporting Hypotheses 3 and 4.

\section{Moderated Mediation Analyses}

While we conducted a mediation analysis in Study 1, we investigated the contingencies of this model in Study 2, that is, we qualified it by adding moderation. Thus, we tested a moderated mediation model by computing the mediation path model from Study 1 while including moderation effects as interaction terms (see e.g., Muller et al. 2005; Edwards and Lambert 2007). More specifically, we estimated a path model in which ethical leadership was related to follower engagement which, in turn, was related to their personal initiative and counterproductive behavior. In this model, we tested whether the relationship between ethical leadership and engagement was moderated by leader Machiavellianism (first stage moderation) (Hypothesis 5). The results of the analysis are shown in Fig. 1.

The variables investigated explained a substantial proportion of the variance both in employee initiative $\left(R^{2}=.17\right)$ and in counterproductive behavior $\left(R^{2}=.13\right)$. The results of the path analysis show-as expected-a significant moderation effect of leader Machiavellianism on the relationship between ethical leadership and work engagement, i.e., the coefficient of the interaction term (ethical leadership $\times$ leader Machiavellianism) was significant $(\beta=-.38, p<.01)$; leader Machiavellianism was not directly related to engagement $(\beta=-.02$, n.s.). Ethical leadership had a significant positive relationship with

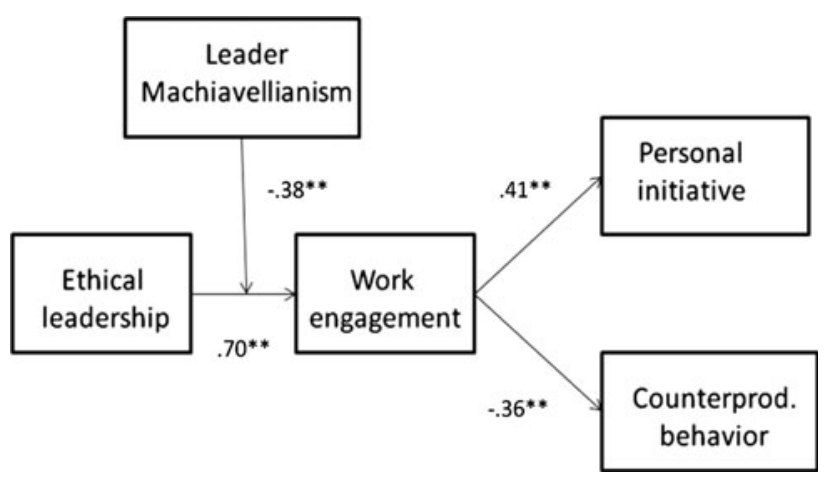

Fig. 1 Results of the moderated mediation analysis (Study 2). Note: Perceptions of ethical leader behavior, work engagement, and counterproductive work behavior were collected as follower ratings; Machiavellian leader personality and followers' personal initiative were collected as supervisor ratings 
engagement $(\beta=.70, p<.01)$. In line with the results from Study 1 , engagement was in turn significantly related to both employee initiative $(\beta=.41, p<.01)$ and employee counterproductive behavior $(\beta=-.36, p<.01)$.

To facilitate the interpretation of the statistically significant interaction effect we plotted high and low regression lines $(+1$ and -1 standard deviation from the mean) as recommended by Cohen and Cohen (1983). The nature of the interaction between ethical leadership and leader Machiavellianism is depicted in Fig. 2. In line with Hypothesis 5, the relationship between ethical leadership behavior and employee work engagement (and thus indirectly also with employee personal initiative and counterproductive behavior) is stronger for leaders low on Machiavellianism, whereas the relationship between ethical leadership and employee work engagement is weaker for leaders high on Machiavellianism.

\section{Additional Moderated Mediation Analyses}

Next, we tested whether the relationship between ethical leadership and both initiative and counterproductive behavior were fully mediated by engagement by adding direct effects of the ethical leadership on the dependent variables. More specifically, we conducted a path analysis as above, but included direct paths from ethical leadership to employee initiative and to counterproductive work behavior. This analysis showed that the additional paths were non-significant for both initiative $(\beta=.16$, n.s.) and counterproductive behavior $(\beta=-.11$, n.s.). The results of a Chi-square difference test further showed that the model including the direct paths did not fit the data significantly better than the model without direct paths described above $\left(\Delta \chi^{2}(2)=4.49\right.$, n.s. $)$.

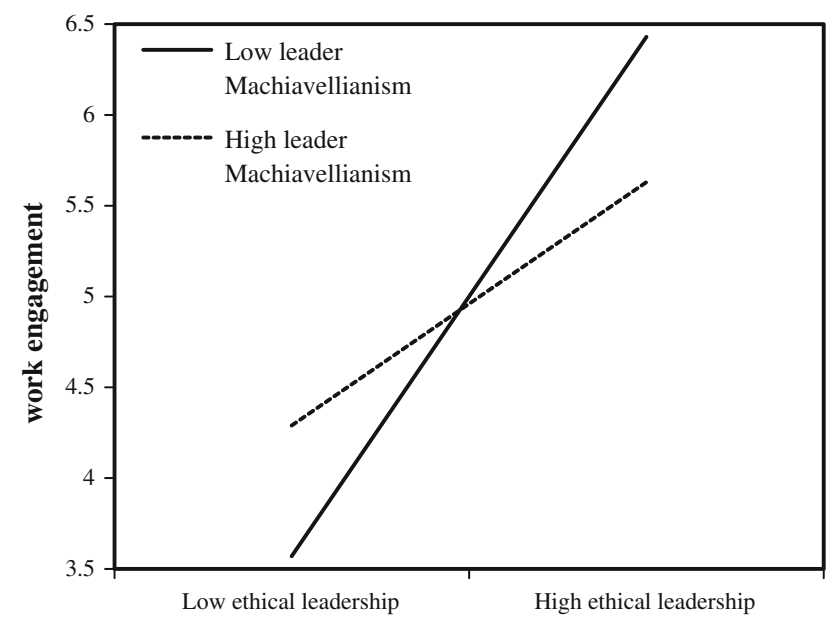

Fig. 2 Plot of interaction effect between ethical leadership and leader Machiavellianism (Study 2)
Finally, we tested a moderated mediation model including all possible interaction effects (i.e., direct effect moderation: ethical leadership * leader Machiavellianism on both personal initiative and counterproductive behavior; first stage moderation: ethical leadership * leader Machiavellianism on work engagement; second stage moderation: work engagement * leader Machiavellianism on both personal initiative and counterproductive behavior). While the first stage moderation effect was significant, the two direct moderation effects and the two second stage moderation effects all proved to be non-significant. Also, the fit of such a full moderation model was significantly worse than the fit of a mediated moderation model including only the first stage moderation: $\Delta \chi^{2}(1)=18.69, p<.01$. In sum, Hypothesis 5 is substantiated; the data support a full mediation model in which only the relationship between ethical leadership and follower work engagement is moderated by leader Machiavellianism.

\section{Discussion}

The first aim of our study was to test the role of work engagement in the ethical leadership process. In two studies, we found that ethical leadership was significantly related to both employee initiative and counterproductive work behavior and that these relationships were mediated by work engagement. Thus, when employees perceived their leaders as acting ethically, these employees also tended to report enhanced engagement in terms of feeling more vigor, dedication, and absorption at work. Also, in turn, these more engaged employees showed more personal initiative and less counterproductive behavior.

These results suggest a strong identification-related motivational component in the ethical leadership process. Ethical leaders affect follower's self-concept and identity by highlighting how follower efforts are linked to attaining important moral goals and values. This makes work more meaningful in followers' eyes. Followers come to see how their effort and behavior at work forms an expression of the moral values they identify with. In other words, work becomes self-expressive (that is, becomes a reflection of followers' identity and self-concept, cf. Shamir et al. 1993) and as such becomes more intrinsically motivating and engaging. This is in line with more recent work in social psychology on group engagement (e.g., Tyler and Blader 2000, 2003; Blader and Tyler 2009) which predicts that people's discretionary behavior depends on the identity information they receive; the identity information, in turn, is determined by their justice perceptions (e.g., fairness, quality of treatment). Psychological engagement acts as a mediator in the relationship between justice perceptions and discretionary behavior (Tyler and Blader 2003). In our 
two studies, we find similarly that work engagement mediates the relationship between ethical leader behavior (characterized among other things by fair and respectful treatment of followers) and positive and negative discretionary behaviors (personal initiative and counterproductive behavior).

In addition, we aimed to test the role of leader Machiavellianism. Machiavellianism in itself is a topic which has been investigated in business ethics (e.g., Ricks and Fraedrich 1999; Schepers 2003). In addition, the relationship between (un)ethical behavior and organizational citizenship behavior (e.g., Ryan 2001), and the conflict between outward leader behavior and privately held moral norms by the leader (e.g., Barling et al. 2008) were also topics studied in the business ethics field. More generally speaking, ethical issues exist when individuals have to decide between alternative behaviors or actions that are differentially (in)consistent with ethical rules, codes, or norms. These rules, codes, and norms may exist at the societal, organizational, group, or individual level. As a personality trait (e.g., Paulhus and Williams 2002), Machiavellianism represents ethical norms at the individual level, and in our second study we investigated the impact of conflicting ethical norms on the individual level (leader Machiavellianism) and the group level (ethical leader behavior) on observers' ethical behavior (follower initiative as pro-social or ethical behavior and counterproductive work behavior as unethical behavior).

We did not find support for the expectation of Brown and Treviño (2006) that leader Machiavellianism is negatively related to ethical leadership. Although we did find a slight negative relationship, it was not significant. It may be that a moderator is involved here, for example, some followers may be sensitive to this trait in the leader while others are not. For example, those high on Machiavellianism themselves may be less negatively affected. However, our null finding also implies that being high on Machiavellianism does not necessarily imply being low on ethical leader behavior in the eyes of followers. This is in line with the research showing that Machiavellians are selfish and goal-driven, but also adaptable, and skilled at creating a positive image if this benefits them. Machiavellians are able to deploy both pro-social and coercive strategies to further their self-interests and they are able to act in a friendly and cooperative manner if they see this behavior as benefiting them (Hawley 2003; Wilson et al. 1996). Our study adds to this literature that Machiavellians also seem able to act out ethical leader behaviors if they see doing so as beneficial to their goals.

As showing ethical leader behaviors may be required more explicitly than before in today's organizations, it is indeed likely that Machiavellian leaders will increasingly see maintaining their ethical image at work as important for their success in the organization. Thus, they may strive to uphold the expressed or public identity as a highly ethical leader even when this is not necessarily commensurate with privately held beliefs and private identities (i.e., the manipulative and deceitful side of Machiavellianism). As noted, this form of 'acting' at work is also found in emotional labor research which shows that privately felt and publicly expressed emotions at work can differ from each other (e.g., Hochschild 1983).

Other work also suggests that people do not always enact their true self or identity. For example, individual differences exist in the propensity to engage in impression management or in other words in deliberate attempts to positively influence others' evaluations and to win their approval (e.g., Day et al. 2002). Work on self monitoring also suggests that people differ in the extent to which they monitor (or in other words try to observe, regulate, and control) the public appearances of self that they display in social settings (cf. Snyder 1987). High self-monitors control the image of who they are that they present to others to suit the social climate around them. They deliberately shape their behavior to match the desired role or image they want to portray, and their private and public identities can thus differ (Day et al. 2002).

We also investigated how followers reacted if a conflict occurred between the leader's expressed, public identity (demonstrated ethical leader behavior) and their private identity (Machiavellian personality). Brown and Treviño (2006, p. 599) already argued that authenticity and selfawareness are not part of the ethical leadership construct. Our results suggest that such leadership can indeed be enacted and perceived by others without being in line with the self of the enactor. Like other forms of leadership, our results suggest that ethical leadership is not always authentic or an expression of truly held values. As mentioned, Dasborough and Ashkanasy (2002) stressed that it is hard for followers to gauge leaders' intentions. Focusing on transformational leaders, they noted that the difference between authentic and pseudo-transformational leadership is not in the behaviors they display but in the often unspoken intentions behind these. Similarly, the intentions of Machiavellians who are trying to act as ethical leaders may not be authentic and honest, but if the behavior they exhibit is highly similar to more authentic ethical leaders, it will be hard for followers to judge the difference. This suggests that Machiavellian leaders are able to stimulate similar motivational processes in their followers as Non-Machiavellians. While Deluga (2001) showed that Machiavellian leaders are often seen as charismatic by followers, we found that Machiavellian leaders are also able to show ethical leaders behaviors toward followers and profit from the motivational effects of such leadership. 
Yet, our findings also suggest that followers do seem to distinguish between authentic and inauthentic displays of ethical leadership in their reactions as the relationship of ethical leadership with engagement and subsequently work behaviors was reduced for highly Machiavellian leaders for whom expressed and private identity are not in line and stronger for less Machiavellian ethical leaders who authentically express their ethical values and moral identity in their leader behavior. Surface acting research argues that expressing emotions that differ from one's true feelings is often difficult and may be experienced as inauthentic by others (Ashforth and Humphrey 1993; Zapf 2002). Similarly, Machiavellians who are surface acting ethical leader behaviors may thus seem less authentic to others as the values expressed are not in line with privately held beliefs and this may shine through and make their leadership less impactful. Additional research is necessary in this area (see Ünal et al. 2012 for additional areas that need future research).

\section{Limitations and Future Research}

As with any study, our research has some limitations. While our study was done in the field, aiding external validity, experimental research is stronger on internal validity. Also, we measured the variables at one specific point in time, whereas certain processes may only unfold over time. For instance, it may be possible that the relationship between ethical leadership and work engagement becomes negative once followers start to consciously realize that Machiavellian leaders "fake" their ethical values and behaviors. Thus, both experimental as well as longitudinal work is needed to strengthen our conclusions and understand how these processes unfold. Also, our cross-sectional design does not allow for testing the direction of causality. Thus, although the process proposed is theoretically plausible, with the leadership or engagement and behaviors links, each could potentially cause the other. Our findings should be interpreted with this in mind, and future experimental and longitudinal research is needed in this area to address this limitation.

Strengths of this study include that it was carried out in a field setting involving different rater sources thus decreasing the potential negative effects of common source bias for the relationships between some of the variables. However, focal employees provided ratings of ethical leadership, work engagement, and counterproductive behavior. Thus, there is potentially the threat of some single source variance in part of the tested model. Most recent empirical work in the domain of common method variance suggests though that statistical corrections for common method bias often yield biased results and should therefore be avoided (Richardson, Simmering, and Sturman
2009). However, we collected data from multiple sources and several of the variables included in our study could not have been measured in other ways. Also, Study 2 tests for interaction effects which are not subject to inflation by measurement error (Busemeyer and Jones 1983; Wall et al. 1996), and we show a similar mediational pattern in two studies which increases the confidence in the validity and robustness of the findings. Despite its limitations, our study provides insights into the role of engagement and identity processes in the relationship between ethical leadership and (counter)productive work behavior and complements previous studies in the domain of ethical leadership (see, for example, Avey et al. 2012). It also calls for attention to the authenticity of the displayed leader behavior.

Open Access This article is distributed under the terms of the Creative Commons Attribution License which permits any use, distribution, and reproduction in any medium, provided the original author(s) and the source are credited.

\section{References}

Ashforth, B. E., \& Humphrey, R. H. (1993). Emotional labor in service roles: The influence of identity. Academy of Management Review, 18(1), 88-115.

Avey, J. B., Wernsing, T. S., \& Palanski, M. E. (2012). Exploring the process of ethical leadership: The mediating role of employee voice and psychological ownership. Journal of Business Ethics. doi:10.1007/s10551-012-1298-2.

Bakker, A. B., Demerouti, E., \& Verbeke, W. (2004). Using the job demands-resources model to predict burnout and performance. Human Resource Management, 43(1), 83-104.

Bakker, A. B., Hakanen, J. J., Demerouti, E., \& Xanthopoulou, D. (2007). Job resources boost work engagement, particularly when job demands are high. Journal of Educational Psychology, 99(2), 274-284.

Barling, J., Christie, A., \& Turner, N. (2008). Pseudo-transformational leadership: Towards the development and test of a model. Journal of Business Ethics, 81(4), 851-861.

Bass, B. M., \& Steidlmeier, P. (1999). Ethics, character, and authentic transformational leadership. Leadership Quarterly, 10(2), $181-217$.

Becker, J. A. H., \& O'Hair, D. (2007). Machiavellians' motives in organizational citizenship behavior. Journal of Applied Communication Research, 35(3), 246-267.

Bentler, P. M. (1990). Comparative fit indices in structural models. Psychological Bulletin, 107(2), 238-246.

Blader, S. L., \& Tyler, T. R. (2009). Testing and extending the group engagement model: Linkages between social identity, procedural justice, economic outcomes, and extra-role behavior. Journal of Applied Psychology, 94(2), 445-464.

Bolino, M. C., \& Turnley, W. H. (2003). More than one way to make an impression: Exploring profiles of impression management. Journal of Management, 29(2), 141-160.

Bolino, M. C., \& Turnley, W. H. (2005). The personal costs of citizenship behavior: The relationship between individual initiative and role overload, job stress, and work-family conflict. Journal of Applied Psychology, 90(4), 740-748.

Brown, M. E., \& Treviño, L. K. (2006). Ethical leadership: A review and future directions. Leadership Quarterly, 17(6), 595-616. 
Brown, M. E., Treviño, L. K., \& Harrison, D. A. (2005). Ethical leadership: A social learning perspective for construct development and testing. Organizational Behavior and Human Decision Processes, 97(2), 117-134.

Browne, M. W., \& Cudeck, R. (1993). Alternative ways of assessing model fit. In K. A. Bollen \& J. S. Long (Eds.), Testing structural equation models (pp. 136-162). Newbury Park, CA: Sage.

Busemeyer, J. R., \& Jones, L. E. (1983). Analysis of multiplicative combination rules when the causal variables are measured with error. Psychological Bulletin, 93(3), 549-562.

Chen, P. Y., \& Spector, P. E. (1992). Relationships of work stressors with aggression, withdrawal, theft, and substance use: An exploratory study. Journal of Occupational and Organizational Psychology, 65(3), 177-184.

Christie, R., \& Geis, F. (1970). Studies in Machiavellianism. New York: Academic Press.

Cohen, J., \& Cohen, P. (1983). Applied multiple regression/correlation analysis for the behavioral sciences (2nd ed.). Hillsdale, NJ: Erlbaum.

Cohen-Charash, Y., \& Spector, P. E. (2001). The role of justice in organizations: A meta-analysis. Organizational Behavior and Human Decision Processes, 86(2), 278-321.

Cooper, S., \& Peterson, C. (1980). Machiavellianism and spontaneous cheating in competition. Journal of Research in Personality, 14(1), 70-75.

Crant, J. M. (2000). Proactive behavior in organizations. Journal of Management, 26(3), 435-462.

Dasborough, M. T., \& Ashkanasy, N. M. (2002). Emotion and attribution of intentionality in leader-member relationships. Leadership Quarterly, 13(5), 615-634.

Day, D. V., Schleicher, D. J., Unckless, A. L., \& Hiller, N. J. (2002). Self-monitoring personality at work: A meta-analytic investigation of construct validity. Journal of Applied Psychology, 87(2), 390-401.

De Hoogh, A. H. B., \& Den Hartog, D. N. (2008). Ethical and despotic leadership, relationships with leader's social responsibility, top management team effectiveness and subordinates' optimism: A multi-method study. Leadership Quarterly, 19(3), 297-311.

Deluga, R. J. (2001). American presidential Machiavellianism: Implications for charismatic leadership and rated performance. Leadership Quarterly, 12(3), 339-353.

Den Hartog, D. N., \& Belschak, F. D. (2007). Personal initiative, commitment and affect at work. Journal of Occupational and Organizational Psychology, 80(4), 601-622.

Den Hartog, D. N., \& De Hoogh, A. H. B. (2009). Empowerment and leader fairness and integrity: Studying ethical leader behavior from a levels-of-analysis perspective. European Journal of Work and Organizational Psychology, 18(2), 199-230.

DePaulo, B. M., \& Rosenthal, R. (1979). Telling lies. Journal of Personality and Social Psychology, 37(10), 1713-1722.

Detert, J. R., Trevino, L. K., Burris, E. R., \& Andiappan, M. (2007). Managerial modes of influence and counterproductivity in organizations: A longitudinal business-unit-level investigation. Journal of Applied Psychology, 92(4), 993-1005.

Dirks, K. T., \& Ferrin, D. L. (2002). Trust in leadership: Metaanalytic findings and implications for research and practice. Journal of Applied Psychology, 87(4), 611-628.

Edwards, J. R., \& Lambert, L. S. (2007). Methods for integrating moderation and mediation: A general analytical framework using moderated path analysis. Psychological Methods, 12(1), 1-22.

Fox, S., \& Spector, P. E. (1999). A model of work frustrationaggression. Journal of Organizational Behavior, 20(6), 915-931.

Fredrickson, B. L. (2001). The role of positive emotions in positive psychology: The broaden-and-build theory of positive emotions. American Psychologist, 56(3), 218-226.
Frese, M., \& Fay, D. (2001). Personal initiative: An active performance concept for work in the 21st century. Research in Organizational Behavior, 23, 133-187.

Frese, M., Fay, D., Hilburger, T., Leng, K., \& Tag, A. (1997). The concept of personal initiative: Operationalization, reliability, and validity in two german samples. Journal of Organizational and Occupational Psychology, 70(2), 139-161.

Frese, M., Kring, W., Soose, A., \& Zempel, J. (1996). Personal initiative at work: Differences between East and West Germany. Academy of Management Journal, 39(1), 37-63.

Gunnthorsdottir, A., McCabe, K., \& Smith, V. (2002). Using the Machiavellianism instrument to predict trustworthiness in a bargaining game. Journal of Economic Psychology, 23(1), 49-66.

Halbesleben, J. R. B. (2010). A meta-analysis of work engagement: Relationships with burnout, demands, resources, and consequences. In A. B. Backer \& M. P. Leiter (Eds.), Work engagement: A handbook of essential theory and research (pp. 102-117). New York: Psychology Press.

Hallberg, U., \& Schaufeli, W. B. (2006). "Same Same" but different? Can work engagement be discriminated from job involvement and organizational commitment? European Psychologist, 11(2), 119-127.

Hawley, P. H. (2003). Prosocial and coercive configurations of resource control in early adolescence: A case for the well adapted Machiavellian. Merrill-Palmer Quarterly, 49(3), 279-309.

Hochschild, A. R. (1983). The managed heart. Berkeley: University of California Press.

Hogg, M. A. (2001). A social identity theory of leadership. Personality and Social Psychology Review, 5(3), 184-200.

Howell, J. M., \& Avolio, B. (1992). The ethics of charismatic leadership: Submission or liberation. Academy of Management Executive, 6(2), 43-54.

Kalshoven, K., \& Den Hartog, D. N. (2009). Ethical leader behavior and leader effectiveness: The role of prototypicality and trust. International Journal of Leadership Studies, 5(2), 102-119.

Kalshoven, K., Den Hartog, D. N., \& De Hoogh, A. H. B. (2011a). Ethical leadership at work questionnaire (ELW): Development and validation of a multidimensional measure. Leadership Quarterly, 22(1), 51-69.

Kalshoven, K., Den Hartog, D. N., \& De Hoogh, A. H. B. (2011b). Ethical leader behavior and big five factors of personality. Journal of Business Ethics, 100(2), 349-366.

Konovsky, M. A., \& Pugh, S. D. (1994). Citizenship behavior and social exchange. Academy of Management Journal, 37(3), 656-669.

Laschinger, H. K. S., \& Finegan, J. (2005). Empowering nurses for work engagement and health in hospital settings. Journal of Nursing Administration, 35(10), 439-449.

Lee, K., \& Allen, N. J. (2002). Organizational citizenship behavior and workplace deviance: The role of affect and cognitions. Journal of Applied Psychology, 87(1), 131-142.

Marcus, B., \& Schuler, H. (2004). Antecedents of counterproductive behavior at work: A general perspective. Journal of Applied Psychology, 89(4), 647-660.

Marsh, H. W., Balla, J. R., \& Hau, K.-T. (1996). An evaluation of incremental fit indices: A clarification of mathematical and empirical properties. In G. A. Marcoulides \& R. E. Schumacker (Eds.), Advanced structural equation modeling: Issues and techniques (pp. 315-353). Mahwah, NJ: Erlbaum.

Mauno, S., Kinnunen, U., \& Ruokolainen, M. (2007). Job demands and resources as antecedents of work engagement: A longitudinal study. Journal of Vocational Behavior, 70(1), 149-171.

Mayer, D. M., Kuenzi, M., Greenbaum, R., Bardes, M., \& Salvador, R. (2009). How low does ethical leadership flow? The relative 
effects of top management and supervisors on employee ethical behaviors and job attitudes. Organizational Behavior and Human Decision Processes, 108(1), 1-13.

Moon, H., Kamdar, D., Mayer, D. M., \& Takeuchi, R. (2008). Me or we? The role of personality and justice as other-centered antecedents to taking charge within organizations. Journal of Applied Psychology, 93(1), 84-94.

Muller, D., Judd, C. M., \& Yzerbyt, V. Y. (2005). When moderation is mediated and mediation is moderated. Journal of Personality and Social Psychology, 89(6), 852-863.

Parry, K. W., \& Proctor-Thomson, S. B. (2002). Perceived integrity of transformational leaders in organisational settings. Journal of Business Ethics, 35(1-2), 75-96.

Paulhus, D. L., \& Williams, K. M. (2002). The dark triad of personality: Narcissism, Machiavellianism, and psychopathy. Journal of Research in Personality, 36(6), 556-563.

Piccolo, R. F., Greenbaum, R., Den Hartog, D. N., \& Folger, R. (2010). Task significance and job autonomy as motivational mechanisms in the ethical leadership process. Journal of Organizational Behavior, 31(2-3), 259-278.

Pillai, R., Schriesheim, C., \& Williams, E. (1999). Fairness perceptions and trust as mediators for transformational and transactional leadership: A two-sample study. Journal of Management, 25(6), 897-933.

Podsakoff, P. M., MacKenzie, S. B., Paine, J. B., \& Bachrach, D. G. (2000). Organizational citizenship behaviors: A critical review of the theoretical and empirical literature and suggestions for future research. Journal of Management, 26(3), 513-563.

Rank, J., Pace, V. L., \& Frese, M. (2004). Three avenues for future research on creativity, innovation, and initiative. Applied Psychology: An International Review, 53(4), 518-528.

Richardson, H. A., Simmering, M. J., \& Sturman, M. C. (2009). A tale of three paradigms: Examining post hoc statistical corrections for common method variance from three divergent perspectives. Organizational Research Methods, 12(4), 762-800.

Ricks, J., \& Fraedrich, J. (1999). The paradox of Machiavellianism: Machiavellianism may make for productive sales but poor management review. Journal of Business Ethics, 20(3), 197-205.

Ross, W. T, Jr, \& Robertson, D. C. (2000). Lying: The impact of decision context. Business Ethics Quarterly, 10(2), 409-440.

Rothbard, N. P. (2001). Enriching or depleting? The dynamics of engagement in work and family roles. Administrative Science Quarterly, 46(4), 655-684.

Ryan, J. J. (2001). Moral reasoning as a determinant of organizational citizenship behaviors: A study in the public accounting profession. Journal of Business Ethics, 33(3), 233-244.

Schaufeli, W. B., \& Bakker, A. B. (2004). Job demands, job resources, and their relationship with burnout and engagement: A multi-sample study. Journal of Organizational Behavior, 25(3), 293-315.
Schaufeli, W. B., Bakker, A. B., \& Salanova, M. (2006). The measurement of work engagement with a brief questionnaire: A cross-national study. Educational and Psychological Measurement, 66(4), 701-716.

Schaufeli, W. B., Salanova, M., Gonzalez-Roma, V., \& Bakker, A. B. (2002). The measurement of engagement and burnout: A two sample confirmatory factor analytic approach. Journal of Happiness Studies, 3(1), 71-92.

Shamir, B., House, R., \& Arthur, M. B. (1993). The motivational effects of charismatic leadership: A self-concept based theory. Organizational Science, 4(4), 577-591.

Schepers, D. H. (2003). Machiavellianism, profit, and the dimension of ethical judgment: A study of impact. Journal of Business Ethics, 42(4), 339-352.

Snyder, M. (1987). Public appearances/private realities: The psychology of self-monitoring. New York: Freeman.

Sobel, M. E. (1982). Asymptotic confidence intervals for indirect effects in structural equation models. In S. Leinhardt (Ed.), Sociological methodology (pp. 290-313). San Francisco: JosseyBass.

Treviño, L. K., Brown, M., \& Hartman, L. P. (2003). A qualitative investigation of perceived executive ethical leadership: Perceptions from inside and outside the executive suite. Human Relations, 56(1), 5-37.

Tyler, T. R., \& Blader, S. R. (2000). Cooperation in groups: Procedural justice, social identities, and behavioral engagement. Philadelphia: Psychology Press.

Tyler, T. R., \& Blader, S. R. (2003). The group engagement model: Procedural justice, social identity, and cooperative behavior. Personality and Social Psychology Review, 7(4), 349-361.

Ünal, A. F., Warren, D. E., \& Chen, C. C. (2012). The normative foundations of unethical supervision in organizations. Journal of Business Ethics. doi:10.1007/s10551-012-1300-z.

Van Dyne, L., \& LePine, J. A. (1998). Helping and voice extra-role behavior: Evidence of construct and predictive validity. Academy of Management Journal, 41(1), 108-119.

Wall, T. D., Jackson, P. R., Mullarkey, S., \& Parker, S. K. (1996). The demands-control model of job strain: A more specific test. Journal of Occupational and Organizational Psychology, 69(2), 153-166.

Walumbwa, F. O., \& Schaubroeck, J. (2009). Leader personality traits and employee voice behavior: Mediating roles of ethical leadership and workgroup psychological safety. Journal of Applied Psychology, 94(5), 1275-1286.

Wilson, D. S., Near, D., \& Miller, R. R. (1996). Machiavellianism: A synthesis of evolutionary and psychological literatures. Psychological Bulletin, 119(2), 285-299.

Zapf, D. (2002). Emotion work and psychological well-being: A review of the literature and some conceptual considerations. Human Resource Management Review, 12, 237-268. 